\begin{tabular}{ll}
\hline \hline MINING AND METALLURGY INSTITUTE BOR & ISSN: 2334-8836 (Štampano izdanje) \\
UDK: 622 & ISSN: 2406-1395 (Online) \\
\hline \hline
\end{tabular}

UDK: $622.7 / .355(045)=111$

doi: $10.5937 / \mathrm{mmeb} 1704021 \mathrm{~T}$

Dejan Todorović, Zoran Bartulović, ${ }^{*}$ Vladimir Jovanović, Branislav Ivošević ${ }^{*}$

\title{
THE BOND WORK INDEX OF LIMESTONE AND ANDESITE MIXTURES ${ }^{* *}$
}

\begin{abstract}
This paper investigates grinding of mineral mixtures with different grindabilities in the Bond ball mill. Understanding the ore mixture grinding is of great importance in mineral processing. The energy required for crushing and grinding is presented by the Bond work index and is determined by means of Bond grindability test. This paper presents the experimental results of the Bond work index values obtained by the standard method on limestone and andesite samples, as well as composite samples made up from these ore in different weight ratios. Comparatively are shown the Bond work index values that are obtained by the mass fraction of components that make up the composite samples calculation and their differences from the real value. During the Bond work index value determining, changes in the composition of the grinding products and circulating mill charge were monitored.
\end{abstract}

Keywords: Bond work index, grinding, circulating charge, composite samples

\section{INTRODUCTION}

Grinding is one of the main industrial processes which burden with the large expenses in the heavy equipment, energy, operation and maintenance. It is necessary to spend the most of energy for ore grinding to the designed size, significantly more than for all the other processes of preparation and concentration. In the mineral processing in terms of energy savings is crucial to understand how the ore mixture with different grindabilities from different deposit parts would grind. Natural minerals and rocks are generally very heterogeneous in their physical characteristics. It is important in the heterogeneous materials comminution to understand how the individual components act separately and, on the other hand, how these components in the mill will affect to each other in order to optimize the grinding process. Further, it is important to understand how ore different mineral components with different grindabilities would react to grinding after their liberation, since different responses of mill load components in the grinding process can lead to formation of adverse granularity for further concentration process.

Ore grindability is represented by the Bond work index value for the purposes of the processes in mineral processing. This value is found in a laboratory Bond ball mill by simulating dry grinding in a closed circuit until the $250 \%$ circulating load has been achieved (Magdalinovic, 2003).

\footnotetext{
* Institute for Technology of Nuclear and other Mineral Raw Materials, 11000 Belgrade, Serbia, d.todorovic@itnms.ac.rs

** This investigation was conducted under the Project TR 33007 "Implementation of the Modern Technical, Technological and Ecological Design Solutions in the Existing Production Systems of the Copper Mine Bor and Copper Mine Majdanpek", funded by the Ministry of Education, Science and Technological Development of the Republic of Serbia
} 
A large number of researchers in their papers deal with various aspects of the mineral mixtures grinding in a ball mill.

Feurstenau and Venkataraman (1988) have performed the grinding experiments in a closed circuit on a quartz and limestone mixture samples. They have shown that it takes 25 two-minute grinding cycles in order to achieve a constant circulating charge, whereby it was constantly changing its, i.e. there is a harder-grinding material concentration in the circulating charge.

Kapur and Feurstenau (1989) have carried out the locked-cycle grinding experiments with a constant grinding time on quartz and limestone samples and their mixtures in different mass portions. They have demonstrated that to achieve the grinding steady state, actually a constant circulating load of single component mill feed needs 3 to 6 grinding cycles, and for mixture of these ingredients up to 35 cycles.

Yan and Eaton (1994) studied the Bond work index changes of ore mixtures as a function of the mixture composition, and found that this value is not the simply weighted - average value for individual component.

Hostels and Avsar (1998) have carried out the experiments by the standard Bond grindability test on samples of clinker and volcanic tuff and their mixtures in various weight ratios. They have shown that the Bond work index value of these components mixtures is greater than the Bond work index of harder components, clinker.

Oner (2000) have conducted a research of clinker and blast furnace slag mixture Bond Work Index in different mass proportions. He found out that these values are always lower than the Bond Index obtained as the mean calculated Bond work index value of mixture components by their mass portion.

Ipek et al. (2005) have carried out the Bond work index measurements by the standard method on samples of quartz, feldspar and kaolin and their binary and ternary mixtures. They have demonstrated that the energy required for comminution is smaller when the mixture components are grinded separately than when they are grinded together as a mixture.

Tavares and Kallemback (2013) on samples of limestone, basalt and copper ore and their mixtures in different mass portions were determined the Bond work index value by the standard Bond's procedure. They found that the energy required for grinding is most often lower when the components mixture grinded separately regarding to the required energy for grinding components together as a mixture.

\section{METHOD AND MATERIAL}

Specification of the Bond's mill, together with the experimental execution conditions of the standard Bond's test are given in Table 1.

Table 1 Bond's mill specification and grinding conditions

\begin{tabular}{|l|c|}
\hline Mill diameter, $\mathrm{D}_{\mathrm{m}}, \mathrm{cm}$ & 30.48 \\
\hline Mill length, $\mathrm{L}_{\mathrm{m}}, \mathrm{cm}$ & 30.48 \\
\hline Number of mill rotations in minutes, $\mathrm{n}, \mathrm{min}^{-1}$ & 70 \\
\hline Mill balls weight, $\mathrm{M}_{\mathrm{b}}, \mathrm{kg}$ & 21.125 \\
\hline Geometry of mill liner & smooth \\
\hline Grinding type & dry \\
\hline $\mathrm{V}_{\text {ore }}, \mathrm{cm}^{3}$ & 700 \\
\hline
\end{tabular}


Andesite and limestone samples were prepared by crushing in a laboratory jaw crusher and roll crusher in a closed cycle with screening to size $100 \%-3,327 \mathrm{~mm}$. The samples of pure andesite and pure limestone are separated from the ground material for experiments. The composite samples of andesite and limestone are made from the rest, in the following ratios:

limestone $:$ andesite $=25: 75$,

limestone $:$ andesite $=50: 50$,

limestone $:$ andesite $=75: 25$.

The Bond work index determination according to the standard Bond's test is done on all these samples with comparative sieve size of 74, 105 and 150 microns. The Bond Work Index is calculated using the formula (Bond, 1961):

$$
W_{i}=1,1 \cdot \frac{44,5}{P_{C}{ }^{0,23} \cdot G^{0,82} \cdot\left(\frac{10}{\sqrt{P_{80}}}-\frac{10}{\sqrt{F_{80}}}\right)}
$$

where:

$W_{i}-$ Bond work index $(\mathrm{kWh} / \mathrm{t})$

$P_{c}-$ test sieve mesh size $(\mu \mathrm{m})$;

$G$ - weight of the test sieve fresh undersize per mill revolution (g/ob);

$F_{80}$ - sieve mesh size passing $80 \%$ of the feed before grinding $(\mu \mathrm{m})$;
$P_{80}$ - opening of the sieve size passing $80 \%$ of the last cycle test sieve undersize product $(\mu \mathrm{m})$.

After each grinding cycle, solubility in $\mathrm{HCl}$ was determined on comparative sieve undersize and thus defined contents of limestone and andesite in the same.

\section{RESULTS AND DISCUSSION}

In order to better understand the mechanisms that occur in the Bond ball mill during the standard Bond grindability test performance on the two-component mineral mixtures, the composition changes of the batch cycles milling products and mill circulating charges were monitored on two-component mineral mixtures

\section{Composition changes of milling product}

Figures 1, 2 and 3 show the grinding product composition changes during the Bond's grinding tests performance using the test sieves 74, 105 and 150 microns on limestone and andesite composite samples with mass ratios 25:75, 50:50, 75:25.

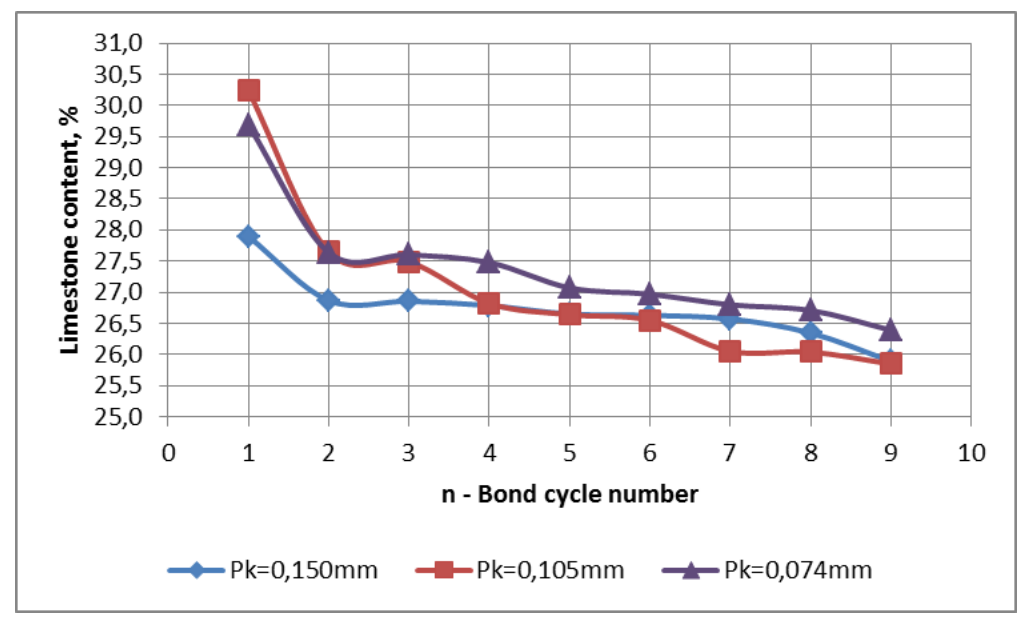

Figure 1 The limestone content in grinding product during the standard Bond test on samples with the composition limestone $:$ andesite $=25: 75$ 


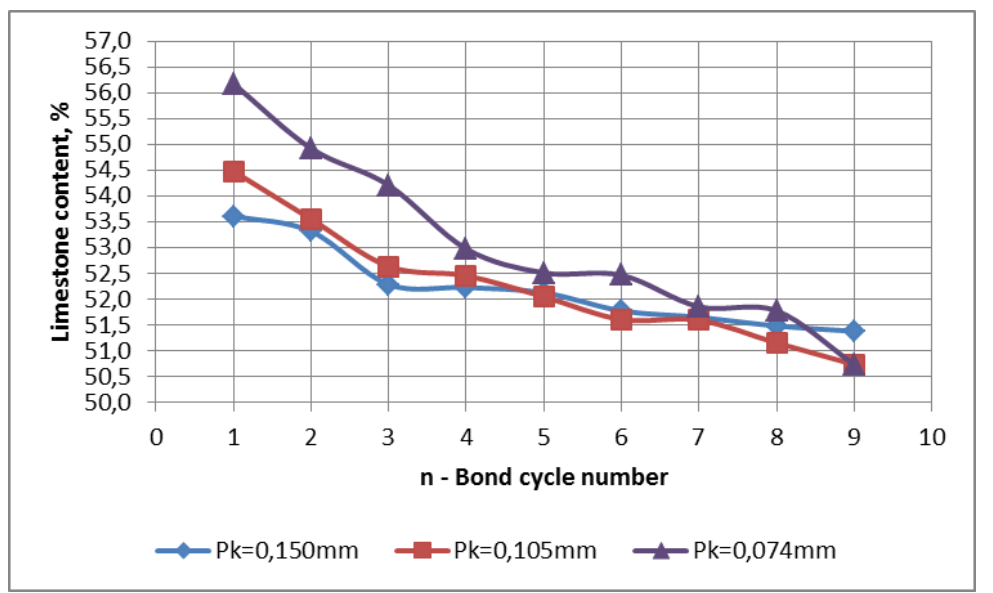

Figure 2 The limestone content in grinding product during the standard Bond test on samples with the composition limestone $:$ andesite $=50: 50$

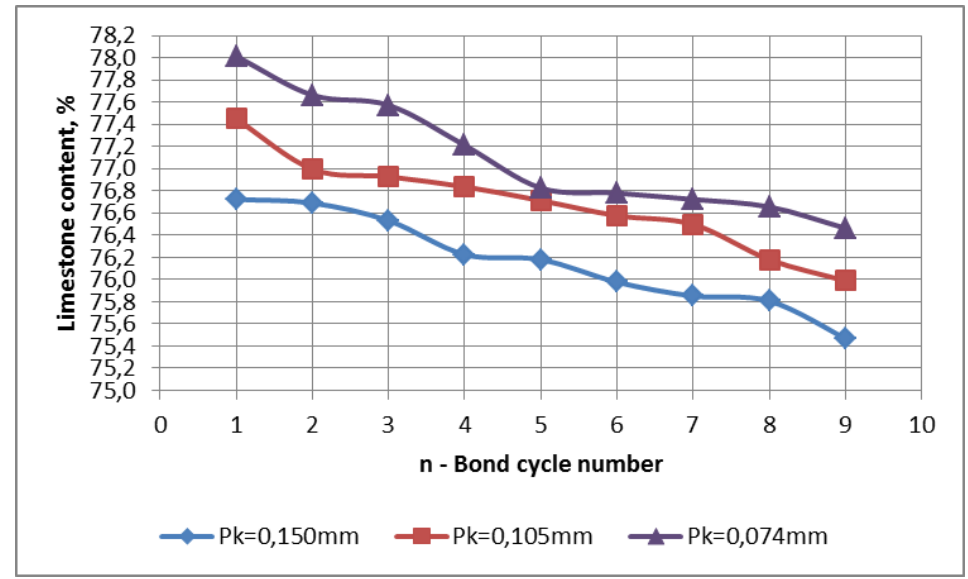

Figure 3 The limestone content in grinding product during the standard Bond test on samples with the composition limestone $:$ andesite $=75: 25$

It can be seen in Figures 1, 2 and 3 that during all Bond tests on samples with varying mass portion of mixtures components with different test sieves, the grinding products of initial grinding cycles have the increased content of soft component (limestone). With increase of grinding cycles, the soft component content (limestone) in the grinding product gradually decreases. At the moment of reaching the steady state $(250 \%$ circulating charge), the content of soft component in the grinding product is equalized by the composition of feed to the grinding process.

\section{Composition changes of circulating charge}

Figures 4, 5 and 6 shows the circulating charge composition changes during the Bond grinding tests using the test sieves 74 , 105 and 150 microns on limestone and andesite composite samples with mass ratios 25:75, 50:50, 75:25. 


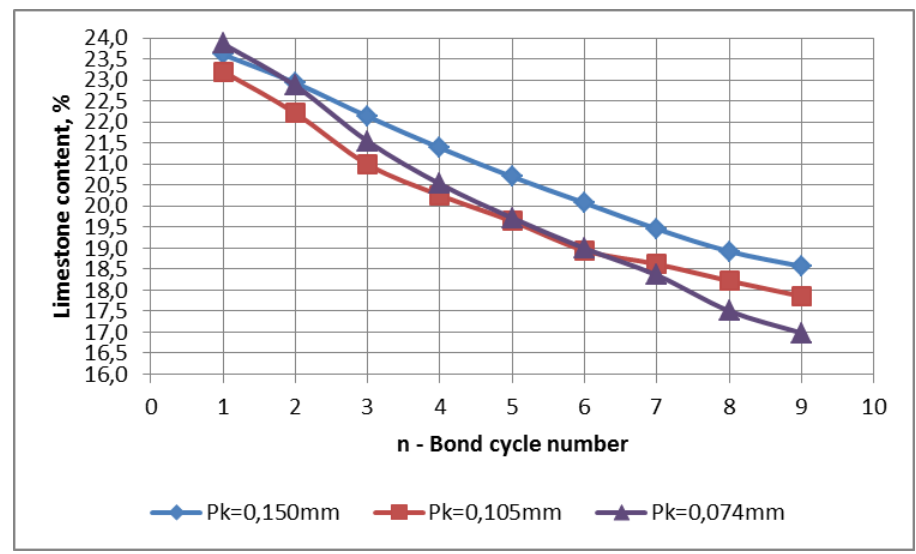

Figure 4 The limestone content in circulating load during the standard Bond test on samples with the composition limestone $:$ andesite $=25: 75$

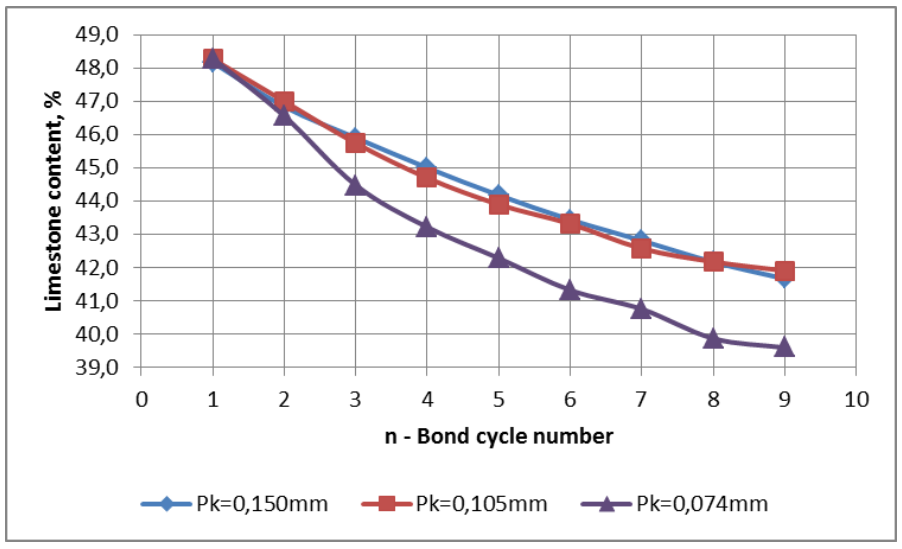

Figure 5 The limestone content in circulating load during the standard Bond test on samples with the composition limestone $:$ andesite $=50: 50$

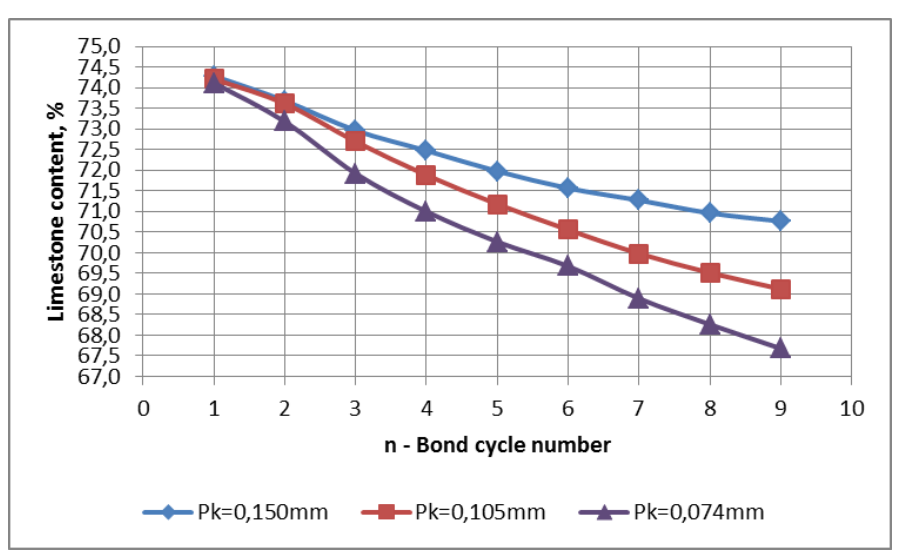

Figure 6 The limestone content in circulating load during the standard Bond test performance on samples with the composition limestone : andesite $=75: 25$ 
It can be seen in Figures 4,5 and 6 that during the execution of all Bond tests on samples with varying mass portion of mixture components and with different test sieves, with an increase in grinding cycle, the mill circulating charge has softer components content (limestone) gradual increase, and harder component content (andesite) gradually decline.

In the initial grinding cycles, the softer component (limestone), which it is easier to grind, quickly reaches the desired size and passes into a grinding product in a larger mass proportion than the harder component (andesite) in relation to their starting mass portions. With the grinding cycles increase, harder component (andesite) accumulate in a mill circulating charge because it more slowly decreases a size. At the moment of reaching the steady state, it forms such a mill circulating charge in which there are the reduced softer component content with a larger mean diameter and an increased harder component content with smaller mean diameter.

\section{The Bond work index of ore mixtures}

Review of the results obtained by performing the Bond grindability tests on samples of limestone and andesite and their composite samples in various weight ratios are shown in Table 1. The Bond work index computational values were obtained using the formula:

$$
W_{i c}=W_{\text {isoft }} \cdot r_{\text {soft }}+W_{i \text { hard }} \cdot r_{\text {hard }}
$$

where:

$W_{i \text { soft }}-$ softer component Bond work index $(\mathrm{kWh} / \mathrm{t})$;

$r_{\text {soft }}-$ mass fraction of softer component (fractions of unit);

$W_{i \text { hard }}-$ harder component Bond work index $(\mathrm{kWh} / \mathrm{t})$;

$r_{\text {hard }}-$ mass fraction of softer component (fractions of unit).

Table 1 The Bond work index values obtained by standard the Bond procedure and values calculated according to the mass fraction of the sample components

\begin{tabular}{|c|c|c|c|c|}
\hline \multirow{2}{*}{ Sample } & $\begin{array}{c}\text { Test sieve, } \\
\mathbf{\mu m}\end{array}$ & $\begin{array}{c}\mathbf{W}_{\mathbf{i}}, \\
\mathbf{k W h} / \mathbf{t}\end{array}$ & $\begin{array}{c}\mathbf{W}_{\mathbf{i}} \text { calcul., } \\
\mathbf{k W h} / \mathbf{t}\end{array}$ & $\begin{array}{c}\text { Difference, } \\
\mathbf{\%}\end{array}$ \\
\hline $\begin{array}{c}\text { Limestone : andesite } \\
\mathbf{1 0 0}: \mathbf{0}\end{array}$ & 74 & 13.90 & $/$ & $/$ \\
\cline { 2 - 5 } & 105 & 12.77 & $/$ & $/$ \\
\cline { 2 - 5 } & 150 & 12.63 & $/$ & $/$ \\
\hline $\begin{array}{c}\text { Limestone : andesite } \\
75: \mathbf{2 5}\end{array}$ & 74 & 14.51 & 14.95 & 3.02 \\
\cline { 2 - 5 } & 105 & 13.91 & 13.81 & -0.72 \\
\hline \multirow{2}{*}{$\begin{array}{c}\text { Limestone : andesite } \\
\mathbf{5 0}: \mathbf{5 0}\end{array}$} & 150 & 13.59 & 13.48 & -0.85 \\
\cline { 2 - 5 } & 105 & 15.50 & 16.00 & 3.19 \\
\hline \multirow{2}{*}{$\begin{array}{c}\text { Limestone : andesite } \\
\mathbf{2 5}: \mathbf{7 5}\end{array}$} & 150 & 14.60 & 14.85 & 1.71 \\
\cline { 2 - 5 } & 74 & 17.03 & 14.32 & 0.42 \\
\cline { 2 - 5 } & 150 & 16.41 & 15.04 & 0.07 \\
\hline \multirow{2}{*}{$\begin{array}{c}\text { Limestone : andesite } \\
\mathbf{0}: \mathbf{1 0 0}\end{array}$} & 74 & 15.13 & 15.17 & -3.17 \\
\cline { 2 - 5 } & 105 & 16.93 & $/$ & 0.23 \\
\cline { 2 - 5 } & 150 & 16.01 & $/$ & $/$ \\
\hline \multicolumn{2}{|c|}{ Mean difference } & & 1.49 \\
\hline
\end{tabular}




\section{CONCLUSION}

It can be seen from Table 1 that the calculated values of the Bond work index are slightly different from the experimen-tally obtained values. Maximum difference between these values is 3\%. Mean diffe-rence is $1.49 \%$, which is within the ope-rational error limits for the Bond grindability test.

According to the previous scientific research, it can be seen that the Bond Index of ore mixtures can not be predicted simply calculating the Bond work index components and their mass portions:

- Yan and Eaton (1994) performed the experiments on two different samples of gold ore, and their mixtures with a large difference in grindability $\mathrm{Wi}=14$ and $\mathrm{Wi}=6$, and they found that it is not possible to predict the computational mixtures of the Bond Index based on components $\mathrm{Wi}$;

- Hosten and Avsar (1998) found that the Wi of clinker and volcanic tuff in different mass ratios mixtures is even greater than harder component $\mathrm{Wi}$;

- Oner (2000) on clinker and blast furnace slag samples, and Tavares and Kallemback (2013) on limestone, basalt and copper ore samples were determined that the mixture $\mathrm{Wi}$ is less than the mean calculated value of components $\mathrm{Wi}$ according to the mass fractions.

- Ipek et al. (2005) on quartz, kaolin and feldspar samples were determined that mixture $\mathrm{Wi}$ is greater than the mean calculated value of components $\mathrm{Wi}$ according to the mass fractions.

In the case of a limestone and andesite mixture samples in different mass ratios, which were examination subject of this study, it can be said that the mean values of component mixture of the Bond work index. according to the mass fraction, corresponds to the real Bond work index values.
On the basis of the obtained data by performing the Bond grindability tests on limestone and andesite composite samples in different mass proportions, it can be concluded:

- In the initial grinding cycles, the soft component content is increased in the grinding product. With each subsequent grinding cycle, this increased soft component content in relation to the initial sample is reduced. Grinding product is equalized by the composition with the starting sample at the moment of reaching the steady state.

- In a circular mill load gradually comes to accumulation of the mixture harder component.

- The Bond work index of experimentally obtained values, and calculated values according to the mixture components mass portions, has the max difference of $3 \%$.

\section{REFERENCES}

[1] Bond F.C., Crushing and Grinding Calculation Parts I and II. British Chemical Engineering 6 (6 and 8), 1961, 378-385 \& 543-548.

[2] Fuerstenau D.W., Venkataraman D.W., The Comminution of Multicomponent Feeds under Batch and LockedCycle Condition: Kinetics, Simulation and Energy Distribution, International Journal of Mineral Processing 22, 1988, 105-118.

[3] Hosten C., Avsar C., Grindability of Mixtures of Cement Clinker and Trass, Cement and Concrete Reasearch, vol.28, no.11, 1998, 1519-1524.

[4] Ipek H., Ucbas Y., Hosten C., The Bond Work Index of Mixtures of Ceramic Raw Materials, Minerals Engineering 18, 2005, 981-983. 
[5] Kapur P.C., Fuerstenau D.W., Simulation of Locked-Cycle Grinding Tests Using Multicomponent Feeds, Powder Technology 58, 1989, 39-48.

[6] Magdalinovic N., Abbreviated Test for Quick Determination of Bond's Work Index, J. Min. And Metall. 39, 2003, 1-4.

[7] Oner M., A study of Intergrinding and Separate Grinding of Blast Furnace
Slag Cement, Cement and Concrete Reasearch 30, 2000, 473-480.

[8] Tavares L.M., Kallemback R.D.C., Grindability of Binary Ore Blends in Ball Mills, Minerals Engineering 41, 2013, 115-120.

[9] Yan D., Eaton R., Breakage Properties of Ore Blends, Minerals Engineering Vol.7, Nos. 2/3, 1994, 185-199. 